\title{
Studying the Role of Physical Education and Sports in Society: a Context with Reference to, Ranikhet (Uttarakhand)
}

\author{
Kumar $\mathbf{A}^{1 *}$ and Sah $\mathbf{R}^{2}$ \\ ${ }^{1}$ Department of Sociology, Govt P G College, India \\ ${ }^{2}$ Department of Physical Education, Govt P G College, India
}

*Corresponding author: Abhimanyu Kumar, Head of the department of Sociology \& Assistant Professor Sociology, Govt. P.G. College, Ranikhet, Uttarakhand, India, Email: kumar_abhi004@ yahoo.co.in

\section{Research Article}

Volume 3 Issue 3

Received Date: August 05, 2020

Published Date: August 18, 2020

DOI: $10.23880 /$ abca-16000127

\section{Abstract}

This paper is based on the primary data collected from the respondent's college of Ranikhet at Almora District of Uttarakhand state of India. All these respondents were randomly selected. The sample included 40respondents sports student and 40respondents related to society which were randomly drawn from college of Ranikhet and city of Ranikhet. Primary data was collected through above stated statistical method affiliation has been measured in terms of degree of reliability. The objective of the paper is conducted through debate and analysis physical education and sports role in the society.

Keywords: Physical Education; Sports; Society; Respondents

\section{Introduction}

The purpose of the physical education is the formation of a physical culture of the man and ability to use various means of physical culture, sports and society in order to maintain and strengthen health, psychophysical preparation and self-preparation for future life and professional activity [1]. Teaching the discipline "physical education" and "sport" in the Surgut branch of oil and gas is carried out in the framework of practical and theoretical training Hillsdon $\mathrm{M}$, et al. [2]. The tasks of studying the discipline are the formation of knowledge of the scientific, biological and practical foundations of physical education and a healthy lifestyle. Physical education brings in more alertness of mind and concentration as they are an essential and vital part of any physical activities and also helps in reducing the reaction time of person Natalia L, et al. [3]. Many people also believe that physical education has the ability to develop the human body in good proportions. Physical education also promote emotional and mental development by helping in overcoming stress, anxiety, tension and various other emotional related problems [4]. Physical education enhances the characteristics of a person and making them fit for a society and enables them to face hardship, endure defeat and take proper decision and risks, which is very much needed in today's competitive world [5].

Jhinjha N, et al. [6] conducted a study on Sports facilities \&infrastructure of government \& private school of Chandigarh. 10government \& private school of Chandigarh were selected as subject for study to examine the sports facility \& infrastructure. The result indicates that private school was having more sports facilities in the term of grounds/courts then government school. Singh $M$, et al. [7] conducted a study of Built existing Sports facilities in engineering college of Chhattisgarh. 50colleges were taken for survey of existing sports facility. 50 technical experts were selected as subject for the study from physical education department of different colleges of Chhattisgarh engineering college. Questionnaire was used to collect review of technical expert to know the sports facility like indoor \& outdoor games in different colleges. It was found that result of indoor games facilities indicated that out of 50 colleges $88 \%$ of the colleges had adequate indoor facilities for games and 
sports whereas only $12 \%$ lacked to provide indoor sports facilities to their pupils. The result shows that colleges are deficiently in require of sports facilities especially the indoor gymnasiums. Nijhawan V, et al. [8] conducted a study of development of physical education curriculum in the light of sports marketing perspectives. The subject of the study was 200 people who belong to society of sports. This study concluded the present curriculum of physical education at higher education is not dynamic and needs revision. It does not have sports marketing which meets the requirements of modern society. A number of inventory of sports were suggested for restructuring the curriculum of physical education.

\section{Objective under Study}

1. The study of debate relates between Respondents-1and Respondents- 2 that, are sports beneficial for society.

2. The study of debate relates between Respondents-1and Respondents- 2 that, are sports health beneficial for society.

3. The study of debate relates between Respondents1and Respondents- 2 that, are sports beneficial for international relationship in society.

\section{Methodology}

A systematic methodology is an important step to any research because it directly influences the validity of the research findings. This precisely describes the methodology tools and instruments adopted in conducting the research. The debate was conducted in Government P.G. College, Ranikhet.

\section{Sample under Study}

The samples of 80respondents of different categories were taken, in which category-1 consists of 40respondents and category- 2 consists of 40respondents. The respondent consists of 40 students and 40people selected through purposive sampling method.

\section{Statistical Analysis of Data}

The collected data was classified and tabulated in accordance with the objectives to drive the meaningful and relevant inferences. The data was analyzed by using statistical techniques like frequency percentage and graphs (Figure 1).

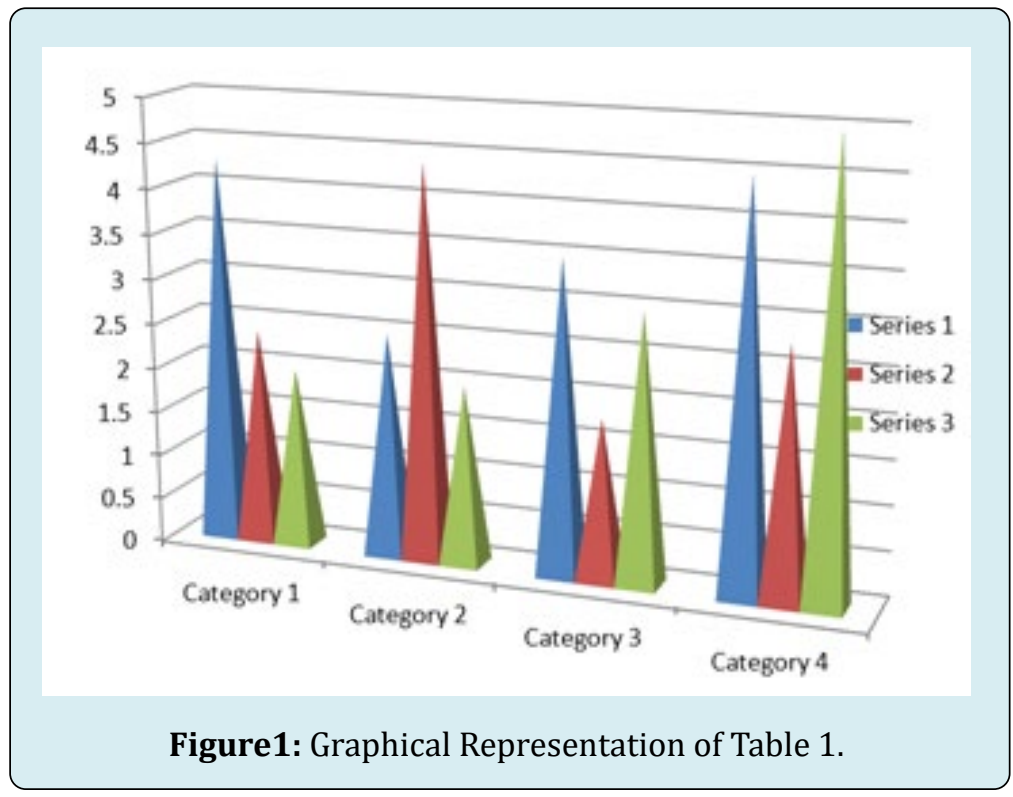

\begin{tabular}{|c|c|c|c|c|c|c|c|c|c|c|c|c|}
\hline \multirow{5}{*}{$\begin{array}{c}\text { Are Sports } \\
\text { Beneficial for } \\
\text { Health }\end{array}$} & \multicolumn{12}{|c|}{ Total Respondents in debate } \\
\hline & \multicolumn{4}{|c|}{$\begin{array}{c}\text { Students (Respondent, } R_{1} \text { ) } \\
\text { Number }=40\end{array}$} & \multicolumn{4}{|c|}{$\begin{array}{c}\left.\text { People(Respondent, } R_{2}\right) \\
\text { Number }=40\end{array}$} & \multicolumn{4}{|c|}{$\begin{array}{l}\text { Total Number of } \\
\text { Respondent }=80\end{array}$} \\
\hline & \multicolumn{2}{|c|}{ Yes } & \multicolumn{2}{|c|}{ No } & \multicolumn{2}{|c|}{ Yes } & \multicolumn{2}{|c|}{ No } & \multicolumn{2}{|c|}{ Yes } & \multicolumn{2}{|c|}{ No } \\
\hline & No. & $\%$ & No. & $\%$ & No. & $\%$ & No. & $\%$ & No. & $\%$ & No. & $\%$ \\
\hline & 27 & 67.5 & 13 & 32.5 & 31 & 77.5 & 9 & 22.5 & 58 & 72.5 & 22 & 27.5 \\
\hline
\end{tabular}

Table1: Debate between Respondents $R_{1} \&$ Respondents $R_{2}$ on topic that are sports beneficial for society. 
The above table shows the debate between students $\left(R_{1}\right)$ and people $\left(R_{2}\right)$ on the topic that are sports beneficial for society. The total number of respondent number $\left(R_{1}\right)$ is 40 and total number of respondents $\left(R_{2}\right)$ is 40 . If inference is drawn from above table total number of respondents in favor are 62 number which is $75.5 \%$ and the number of respondents which are not in favor are 18 in number which $22.5 \%$. Therefore, it can be concluded that respondents in favor> respondents not in favor. Thus it can be said sports are beneficial for society (Figure 2).

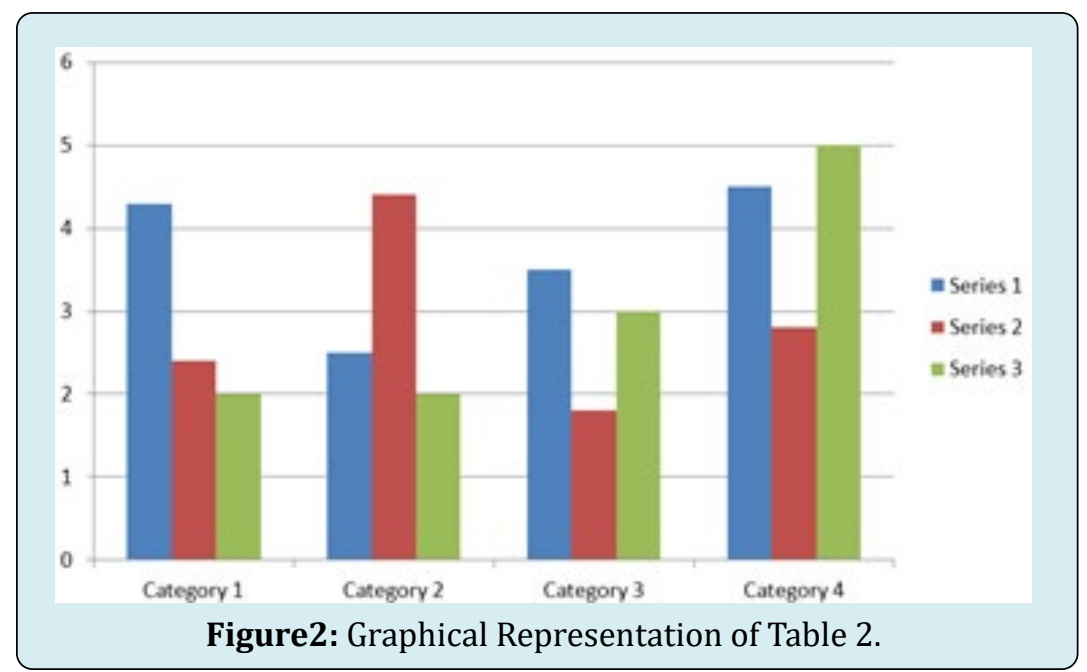

\begin{tabular}{|c|c|c|c|c|c|c|c|c|c|c|c|c|}
\hline \multirow{5}{*}{$\begin{array}{c}\text { Are Sports } \\
\text { Beneficial for } \\
\text { Health }\end{array}$} & \multicolumn{12}{|c|}{ Total Respondents in Debate } \\
\hline & \multicolumn{4}{|c|}{$\begin{array}{c}\text { Students(Respondent, } R_{1} \text { ) } \\
\text { Number }=40\end{array}$} & \multicolumn{4}{|c|}{$\begin{array}{c}\text { People(Respondent, } R_{2} \text { ) } \\
\text { Number }=40\end{array}$} & \multicolumn{4}{|c|}{$\begin{array}{l}\text { Total Number of } \\
\text { Respondent }=80\end{array}$} \\
\hline & \multicolumn{2}{|c|}{ Yes } & \multicolumn{2}{|c|}{ No } & \multicolumn{2}{|c|}{ Yes } & \multicolumn{2}{|c|}{ No } & \multicolumn{2}{|c|}{ Yes } & \multicolumn{2}{|c|}{ No } \\
\hline & No. & $\%$ & No. & $\%$ & No. & $\%$ & No. & $\%$ & No. & $\%$ & No. & $\%$ \\
\hline & 27 & 67.5 & 13 & 32.5 & 31 & 77.5 & 9 & 22.5 & 58 & 72.5 & 22 & 27.5 \\
\hline
\end{tabular}

Table 2: Debate between Respondents $R_{1}$ \& Respondents $R_{2}$ on topic that is sports health beneficial for society.

The above table shows the debate between students $\left(R_{1}\right)$ and people $\left(R_{2}\right)$ on the topic that are sports beneficial for society. The total number of respondent number $\left(R_{1}\right)$ is 40 and total number of respondents $\left(R_{2}\right)$ is 40 . If inference is drawn from above table total number of respondents in favor are 58 number which is $72.5 \%$ and the number of respondents which are not in favor are 22 in number which $27.5 \%$. Therefore, it can be concluded that respondents in favor> respondents not in favor. Thus it can be said health are beneficial for society (Figure 3).

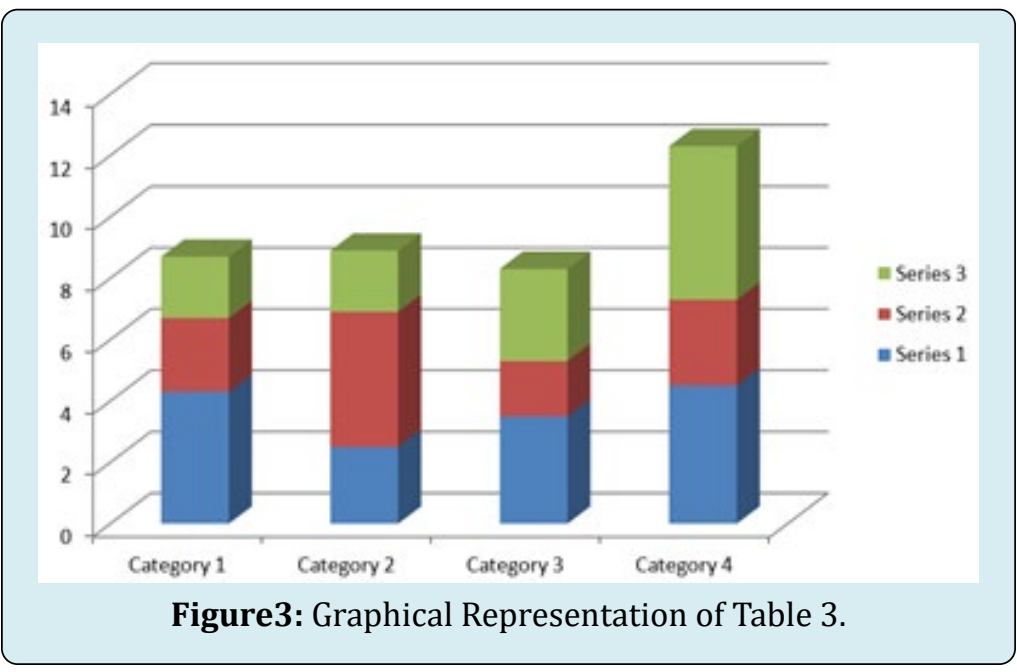

Kumar A and Sah R. Studying the Role of Physical Education and Sports in Society: a Context with Reference to, Ranikhet (Uttarakhand). Ann Bioethics Clin App 2020, 3(3): 000127. 


\begin{tabular}{|c|c|c|c|c|c|c|c|c|c|c|c|c|}
\hline \multirow{5}{*}{$\begin{array}{c}\text { Are Sports } \\
\text { Beneficial for } \\
\text { International } \\
\text { Relation }\end{array}$} & \multicolumn{12}{|c|}{ Total Respondents in Debate } \\
\hline & \multicolumn{4}{|c|}{$\begin{array}{c}\text { Students(Respondent, R1) } \\
\text { Number }=40\end{array}$} & \multicolumn{4}{|c|}{$\begin{array}{c}\text { People(Respondent,R2) } \\
\text { Number }=40\end{array}$} & \multicolumn{4}{|c|}{ Total Number of Respondent $=80$} \\
\hline & \multicolumn{2}{|c|}{ Yes } & \multicolumn{2}{|c|}{ No } & \multicolumn{2}{|c|}{ Yes } & \multicolumn{2}{|c|}{ No } & \multicolumn{2}{|c|}{ Yes } & \multicolumn{2}{|c|}{ No } \\
\hline & No. & $\%$ & No. & $\%$ & No. & $\%$ & No. & $\%$ & No. & $\%$ & No. & $\%$ \\
\hline & 22 & 55 & 18 & 45 & 15 & 37.5 & 25 & 62.5 & 37 & 46.3 & 43 & 53.7 \\
\hline
\end{tabular}

Table 3: Debate between Respondents $R_{1}$ \& Respondents $R_{2}$ on topic that is sports beneficial for maintaining international relationship.

The above table shows the debate between students $\left(\mathrm{R}_{1}\right)$ and people $\left(R_{2}\right)$ on the topic that are sports beneficial for society. The total number of respondent number $\left(R_{1}\right)$ is 40 and total number of respondents $\left(\mathrm{R}_{2}\right)$ is 40 . If inference is drawn from above table total number of respondents in favor are 37 number which is $46.3 \%$ and the number of respondents which are not in favor are 43 in number which $53.7 \%$. Therefore, from above debate between two respondents it can be concluded that respondents in favor<respondents not in favor. Thus it can be said that sports play vital role in maintaining international relationship which are beneficial for society.

\section{Conclusion}

The purpose of the physical education is the formation of a physical culture of the man and ability to use various means of physical culture, sports and society in order to maintain and strengthen health, psychophysical preparation and self-preparation for future life and professional activity. If inference is drawn from above table total number of respondents in favor are 62number which is $75.5 \%$ and the number of respondents which are not in favor are 18 in number which $22.5 \%$. Therefore, it can be concluded that respondents in favor> respondents not in favor. Thus it can be said sports are beneficial for society. If inference is drawn from above table total number of respondents in favor are 58 number which is $72.5 \%$ and the number of respondents which are not in favor are 22 in number which $27.5 \%$. Therefore, it can be concluded that respondents in favor $>$ respondents not in favor. Thus it can be said health are beneficial for society. When inference is drawn from above table total number of respondents in favor are 37 number which is $46.3 \%$ and the number of respondents which are not in favor are 43 in number which $53.7 \%$. Therefore, it can be concluded that respondents in favor $<$ respondents not in favor. Thus it can be said international relationship are beneficial for society.

\section{References}

1. Steven A, Cowburn G, Foster C (2006) Understanding participation in sport and physical activity among children and adults: A review of qualitative studies. Health Educ Res 21(6): 826-835.

2. Hillsdon M (2005) Physical Activity in: The cochrane library. Oxford: update software.

3. Natalia LI (2019) Teaching the Discipline "Physical Culture and Sports" in a Technical University: theoretical aspect. Journal of critical reviews 7(1): 311-313.

4. Korvin S (2007) Functions of professional physical culture and their characteristics. Bulletin of sports science.

5. Swain C (2013) Status of Physical Education Programme in degree Colleges in Odisha: A Study. Scholarly research journal for interdisciplinary studies 2(15): 2198-2205.

6. Narender J (2015) A study of calories intake of government and private school boys of Chandigarh. International journal of physical education, health and social science 3(2): 1-3.

7. Mejar S (2014) History of physical education. Malti publication: Kolhapur.

8. Nijhawan V (2008) A study of development of physical education curriculum in the light of sports marketing perspective: Retrieved on January.

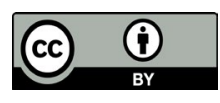

